\title{
The Application of Mixed Teaching Mode based on SPOC in University Information Technology Course
}

\author{
Jianmin Wang \\ Linyi University, Linyi, Shandong, China \\ sdfxwjm@163.com
}

Keywords: SPOC; mixed teaching mode; university information technology course; MOOC,

\begin{abstract}
SPOC is a new online learning platform in the post MOOC period, inherited the advantages of MOOC, but also has the new characteristics of the development of the times. The application of mixed teaching mode based on SPOC in university information technology coursecan effectively improve the teaching effect of the course of information technology, cultivate the basic knowledge of computer science, good information literacy and hands-on ability. This paper introduces a hybrid teaching model based on SPOC, and analyzes its application in the course of information technology in University, which provides a reference for the reform of teaching and learning of information technology course.
\end{abstract}

\section{Introduction}

With the continuous development of Internet technology and the continuous progress of educational informatization in our country, the teaching of university information technology curriculum must meet the needs of the development of the times and make full use of educational information technology to speed up the reform of education and teaching mode.The"New Media Alliance Horizon Report: 2015 Higher Education Edition", jointly organized by the New Media Alliance and the American Association of Educational Informatics, points out the trend of higher education development, important challenges and the development of educational information technology in the next five years. Among them, the mixed teaching mode is considered to be one of the six major trends in the promotion of higher education reform in the next five years. The emergence of SPOC provides a new way of thinking and practical application. The"theorization+practice" of university information technology determine that the teaching mode of traditional classroom can't meet the students' demand for information technology knowledge obviously. This paper puts forward the application of mixed teaching mode based on SPOC in university information technology curriculum to explore the teaching mode of information technology course which meets the needs of the times and college students.

\section{Analysis of Mixed Teaching Mode Based on SPOC}

Since 2000, with the acceleration of the process of global education information, Massive Open Online Courses began sweeping the world. However, following the "MOOC Year" in 2012, the rapid rise of online courses and online enrollment led to the crisis of online courses and learning quality. ${ }^{[1]}$ At present, Small Private Online Course is a popular online learning platform in education and academia. The application of SPOC in education and teaching marks the arrival of the post-MOOC era.SPOC was first proposed by Professor Amand Fokker of the University of California at Berkeley and colleges at home and abroad have begun to use SPOC method to assist teaching.

Mixed teaching model is not a new concept.In recent years, due to the amazing pace of development of information technologygradually make "traditional classroom + online education" mixed teaching model become "king".Mixed teaching mode in China is mainly composed of face to face classroom learning and online course, it should be to achieve an organic combination of the traditional classroom teaching and online learning to achieve better teaching effect. The mixed teaching mode based on SPOC can fully reflect the "theoretical + practical" characteristics of 
university information technology courses, which is conducive to college students master the basic knowledge of computer science, and can effectively improve the computer application ability and promote the comprehensive development of contemporary college students.

\section{The Application of Mixed Teaching Mode based on SPOC in University Information Technology Course}

The mixed teaching mode based on SPOC in the university information technology courses are mainly used in offline teaching module, SPOC online teaching platform and teaching evaluation reflection module.

\subsection{Offline Teaching Module}

The offline teaching module in mixed teaching mode can adopt the basic teaching idea of "flip classroom", and combine group learning, heuristic teaching, graded teaching, problem learning and other teaching methods to achieve the established teaching objectives. It makes teachersa learning aids from the classroom leader. Teachers should create a good learning atmosphere for students and focus on questioning and eliminating confusion link up, prepare the corresponding teaching activities to improve students' learning effectaccording to the results of data analysis of SPOC online learning.

\subsection{SPOC Online Teaching Platform}

Online learning includes watching the teaching video, completing online tasks, participating in online testing, online communication and others. The mixed teaching mode based on SPOC is applied to the online learning platform of teaching resources module, online test module, discussion module and learning analysis module.

\subsubsection{Teaching Resources Module}

The design of teaching resources based on SPOC can integrate the excellent curriculum resources on the MOOC platform, and can also be designed according to the professional needs of students, so as to make the teaching content of information technology more abundant and comprehensive. In order to meet the needs of students, teaching resources module should be divided into compulsory teaching content and elective contentbased on the syllabus. ${ }^{[2]}$

\subsubsection{Online Test Module}

The SPOC online test module under the mixed teaching mode is divided into two categories: academic test and post-test.The academic test is a small quiz in the student's online learning process. Post-test is a comprehensive examination of the overall grasp of the students after the end of the teaching. The two kind of online test can grasp the overall learning content of students, and then analyze the shortage of teaching design to provide valuable experience for online learning.

\subsubsection{Discussion Module}

The discussion module is an online learning exchange platform dedicated to students and teachers.Students can share their learning experience after class, and conditional colleges can hire instructors to manage SPOC's online discussion module.Online discussion module can solve the confusion of college students in learning information technology curriculum, so that students learn time has been a reasonable extension, and it is conducive to play the autonomy of students learning, reflecting the student's dominant position.

\subsubsection{Learning Analysis Module}

SPOC online learning platform can be used to record the whole process of students' learning. The use of artificial intelligence and large data analysis techniques can be used to summarize useful information hidden in the learning process for online learning students and teachers.Teachers can grasp students' learning progress through the learning analysis module, develop offline teaching content according to the analysis of the results of the online test.In addition, learning resources push functioncan also be added in the learning analysis module of SPOC.

\subsection{Teaching Evaluation Reflection Module}

The SPOC mixed teaching mode applied to the university information technology curriculum constructs a perfect and effective reflection modulebased on a variety of evaluation methods. 


\subsubsection{Classroom Teaching Evaluation}

The classroom teaching evaluation uses the final evaluation to evaluate the students. The enthusiasm of the members of the group, the effectiveness of solving problem, whether to achieve common progress can be used as the basis for evaluation. Classroom teaching evaluation system can also increase the proportion of hands-on operations appropriately with attaching importance to theoretical test.

\subsubsection{Teaching Evaluation of Online Learning}

Teachers can make use of SPOC online learning platform of the comprehensive evaluation system, combined with the actual learning situation of the students in the class to develop online evaluation rubric in line with the characteristics of the class, to achieve online automatic scoring.University information technology courses involve more knowledge points, so we can take advantage of the teaching evaluation of online learning to integrate the results of the online test after each course is completed and evaluate the course based on the feedback given by the platform.In addition, the progress of students in the online courses of information technology, the performance in the discussion module can be used as consideration factors.

\section{Conclusion}

The mixed teaching mode based on SPOC can be applied to all aspects of the university information technology curriculum, and the integration of online and offline learning methods can effectively improve the comprehensive literacy of college students' information technology. Institutions of higher learning must combine the professional characteristics and teaching objectives to apply mixed teaching model based on SPOC to university information technology courses, so as to improve the teaching quality of university information technology courses.

\section{References}

[1]. Yin Hedong. Discussion on the Mixed Teaching Mode Based on the Pan-Asian SPOC Platform in the Period of "Post-MOOC" [J]. Modern Educational Technology, 2015, (11): 53-59.

[2]. Chang Yaohui. Teaching reform and practice of programming based on SPOC mixed teaching mode: Taking "Visual Basic " as an example [J]. education of industry and information technology, 2017, (01): 26-32.

[3]. Zhang Ying. Research on the flip classroom model based on "SPOC + task-driven" [J] .Computer Education, 2017, (01): 131-135.

[4]. Xu Wei, Jia Yongzheng, [US] Armando - Fox, [US] David Patterson. from MOOC to SPOC Research From the MOOC to the SPOC - based on the University of California, Berkeley and Tsinghua University MOOC practice of academic dialogue [J]. Modern distance education, 2014, (04): $13-21$ 